\title{
Quality of Scientific Activity, Technology Transfer and Research Integrity: Case of Ukrainian University
}

http://doi.org/10.21272/bel.5(4).101-109.2021

Artem Artyukhov, ORCID: https://orcid.org/0000-0003-1112-6891

$\mathrm{PhD}$, Associated Professor, Sumy State University, Ukraine

Jan Krmela, ORCID: https://orcid.org/0000-0001-9767-9870

$\mathrm{PhD}$, Associated Professor, University of Pardubice, Czech Republic

Vladimira Krmelova

PhD, Associated Professor, Alexander Dubček University of Trenčín, Slovak Republic

Iurii Volk, ORCID: https://orcid.org/0000-0002-0262-762X

$\mathrm{PhD}$, Sumy State University, Ukraine

\begin{abstract}
The article analyzes the relationship between the concepts "quality of scientific activity", "technology transfer" and "research integrity". The main task of research is to offer practical tools for maintaining research integrity as elements of the internal and external quality assurance system of education and research. One of the working hypotheses of the study is the correlation between the quality of educational activities at the university, the quality of research and the level of interest of customers of innovative developments in the process of transfer and commercialization of research results. The first two components are determined by the "purity" of research through the implementation of the principles of research integrity. The schematic relationship between the individual goals of sustainable development characterizes the relationship "university - the quality of research - technology transfer - industry". A logical scheme between research integrity, technology transfer and procedures for internal and external research quality assurance is proposed. The abstract-logical method and the method of induction-deduction were used to analyze the relationship between the concepts of "quality of scientific activity", "technology transfer" and "research integrity". Bibliometric analysis was performed using SciVal and VOSviewer tools based on data from the scientific-metric databases Scopus and Web of Science. Based on the bibliometric analysis, it was found that the query "research integrity" identifies the main violations of research integrity and shows a strong link between the quality of research and success in the transfer of knowledge and technology from university to industry. The main problems of the development of technology transfer between the university and industry at the national level are analyzed. A separate block of problems related to research integrity is identified. The case of the national university on creation of university system of maintenance of research integrity and development of infrastructure of maintenance of scientific activity within the limits of the specified system is resulted. The results of the work can be useful for the triangle "business education-science" to reconcile the interests of all the "vertices" of the triangle under the mandatory condition - ensuring the quality of educational and research activities in universities as centers of intellectual potential.
\end{abstract}

Keywords: Technology Transfer, Sustainable Development, Research Integrity, Research Quality, Business University Model.

JEL Classification: I25, O32, P46.

Cite as: Artyukhov, A., Krmela, J., Krmelova, V., Volk, I. (2021). Quality of Scientific Activity, Technology Transfer and Research Integrity: Case of Ukrainian University. Business Ethics and Leadership, 5(4), 101-109. http://doi.org/10.21272/bel.5(4).101-109.2021.

Received: 07 November 2021

Accepted: 12 December 2021

Published: 30 December 2021

Copyright: (C) 2021 by the author. Licensee Sumy State University, Ukraine. This article is an open access article distributed under the terms and conditions of the Creative Commons Attribution (CC BY) license (https://creativecommons.org/licenses/by/ 4.0/). 


\section{Introduction}

Creating an effective technology transfer model from universities to the industry is mostly considered at the stage of scientific investigation commercialization, without considering the actual creation of scientific products and research integrity principles at this stage. This approach does not allow to study the research quality. Still, it only shows the result of the university activity in the final form - research with varying degrees of readiness for implementation (technological level of TRL readiness and innovative level of IRL readiness). This paper attempts to analyze the technical basis for scientific investigation creation in terms of the "process" approach to the quality of scientific research and research integrity. The proposed method (Figure 1) enables to create a comprehensive algorithm for achieving a high level of commercialization of research results.

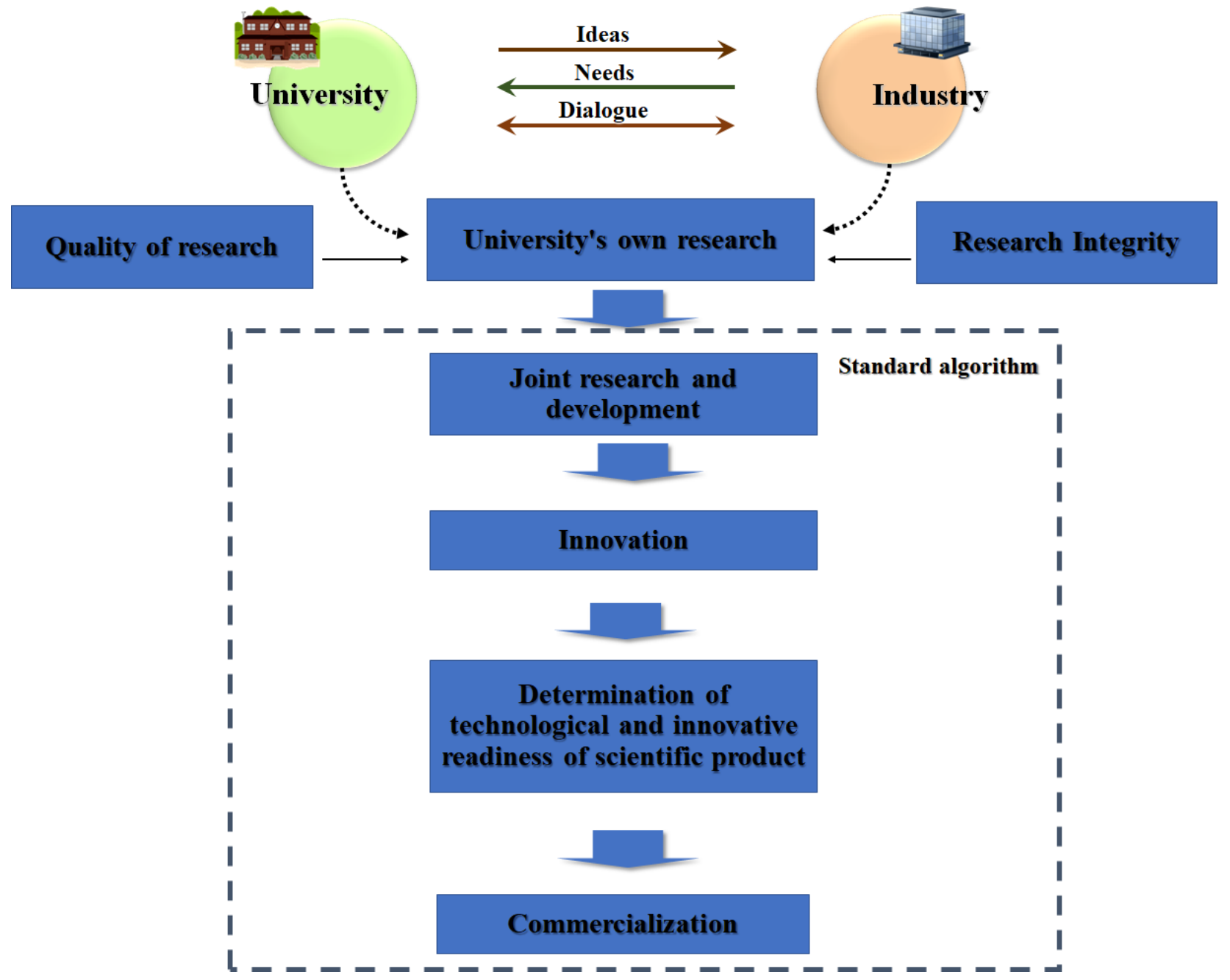

Figure 1. Standard and Improved Mechanism of Technology Transfer in the Triangle "Business Education-Science" Source: Compiled by the authors

\section{Literature Review}

The paper (Arenas et al., 2018) presents a conceptual model of interaction "university - industry", which considers the peculiarities of transfering knowledge and technology from supplier to customer. This model can be detailed in terms of identifying additional tasks of the transfer center in the evolution of development on the path "idea - market". Such tasks, in addition to the actual transfer, are to create the visibility of scientific results through publishing activities, protection of intellectual property rights, international grant activities etc. All these measures with specific proposals for the financial security model should be described in the transfer center activity model. Some works (Pujotomo et al., 2018; Miller et al., 2018) provide a basis for the analysis of statistical materials on publications on technology transfer and its place in the university activities. The role of the university in shaping the landscape of effective implementation is described in (Piroozi, 2017; Schrankler, 2018; Li et al., 2020; Govind, 2016), but these works mostly consider the relationship between the "supplier" of technology (university) and "customer" (industry). Activities of technology transfer centers (Weckowska, 2015; Fauzan et al., 2019), description of the mechanisms for commercialization of intellectual property rights of the university (Daniel et al., 2020) and the relationship between educational and scientific 
environment in this process (Van der Heiden et al., 2015; Cabaleiro-Cerviño et al., 2020) allow us to assert the transfer of the dominant mechanism in the world practice.

The project is based on the previous studies of the author's team, which, in particular, are devoted to:

$>$ creation of successful models of knowledge and technology transfer;

$>$ ensuring the quality of educational activities at the university and building a business-type university model;

$>$ description of the dynamic system "quality of education" using approaches to software testing, determining the technological and innovative level of readiness for implementation;

$>$ ensuring a high level of research and their further commercialization through the creation of a university system to ensure research integrity;

$>$ determining the cause-and-effect relationships in the link "Ossetia quality - socio-economic development of the state" using the Isikawa diagram, Deming cycle and other tools;

$>$ the use of analogies between physical and economic processes to create a model of university activities in the triangle "business-education-science";

creation of roadmaps for the development of education quality assurance systems.

Ensuring research integrity in creating scientific products in the modern scientific literature is reflected exclusively in terms of the violations and measures to influence violators (Coeli et al., 2018; Edwards et al., 2017; Liuta et al., 2017). The place of research integrity in research methodology (Schoenherr, 2015; Shaw et al., 2018) and indicators of scientific activity, including the research and education quality ensuring (Dźwigol, 2021; Porev et al., 2016; Mazurkiewicz et al., 2017; Leahey et al., 2016). However, the relationship between research integrity and technology transfer has not been studied yet. This relationship should establish a bibliometric analysis presented in this paper. It is necessary to provide a mechanism for linking the triangle "businesseducation-science" to achieve sustainable development (global goal) and external quality assurance. activities (local task) to ensure the completeness of the picture and reflect current trends in solving global and local problems of the university scientific activity.

\section{Methodology and Research Methods}

The abstract-logical method and the induction-deduction method were used to analyze the relationship between the concepts "scientific activity quality", "technology transfer," and "research integrity". Bibliometric analysis was performed using SciVal (https://www.scival.com/) and VOSviewer (https://www.vosviewer.com/) based on data from scientific and metric databases Scopus (https://www.scopus.com/) and the Web of Science (https://www.webofscience.com/). One of the working hypotheses of the study is the correlation between the educational activity quality at the university, the research quality, and the customers' interest in innovative investigations in transferring and commercing research results. The first two components are determined by the "purity" of research through the implementation of the research integrity principles.

\section{Results}

The results of bibliometric analysis of the key phrase "research integrity" were conducted according to several criteria and using different data sets. The main task of bibliometric analysis is to check the possible link between research integrity and technology transfer. At the first stage, the bibliographic analysis tool VOS Viewer conducted a comparative study of articles downloaded from the Scopus database (1800 articles for the entire indexing period, keywords with a reference frequency of at least ten times) and Web of Science (1700 articles for the whole period of indexing, keywords with a frequency of at least five times) by exact match in the title and/or abstract of the phrase "research integrity" (Figure 2 and 3). 


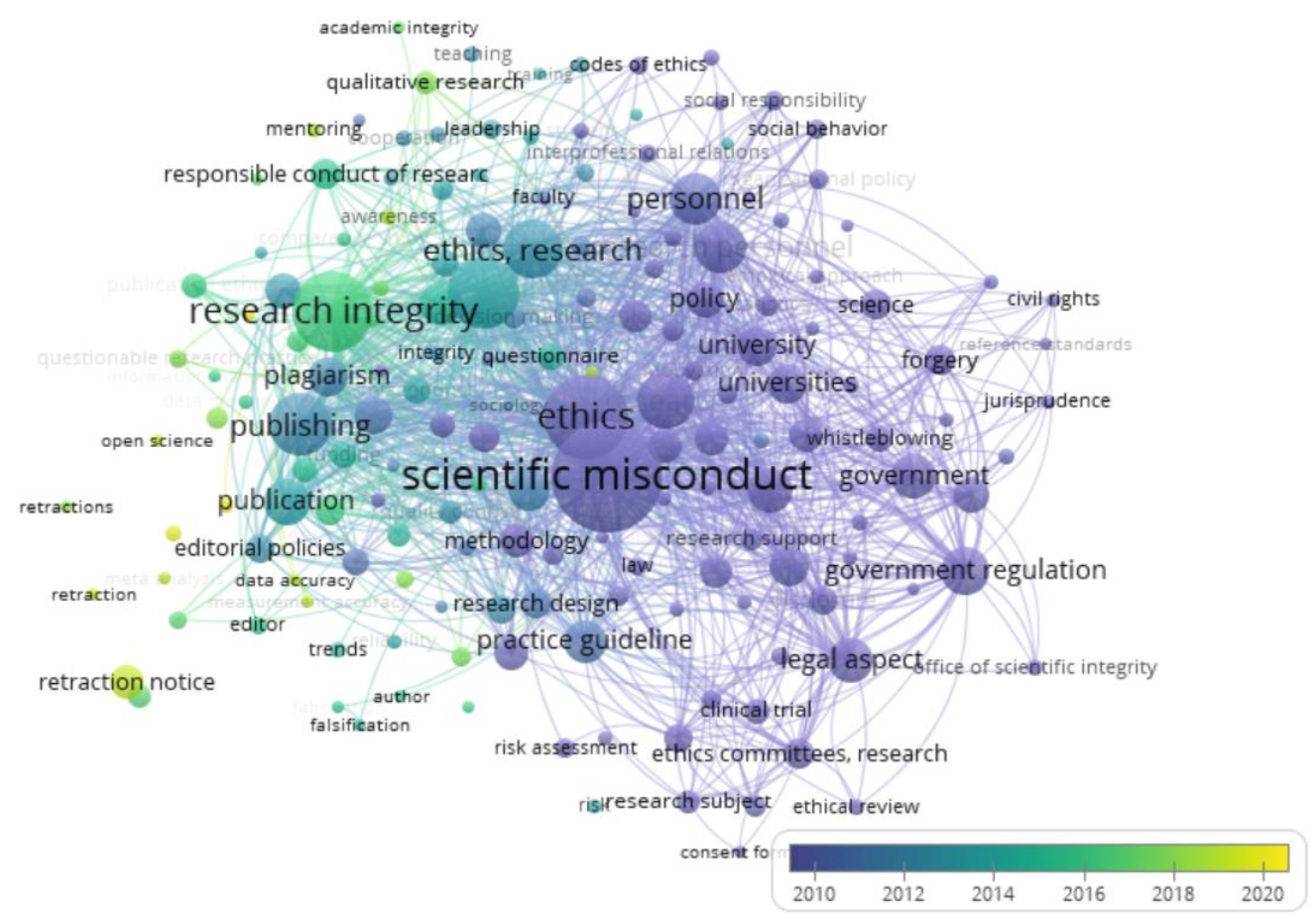

Figure 2. Results of Constructing a Map of Keywords Related to the Query "Research Integrity" (Data - Scopus Database, Map Building Tool - VOS Viewer)

Source: Compiled by the authors

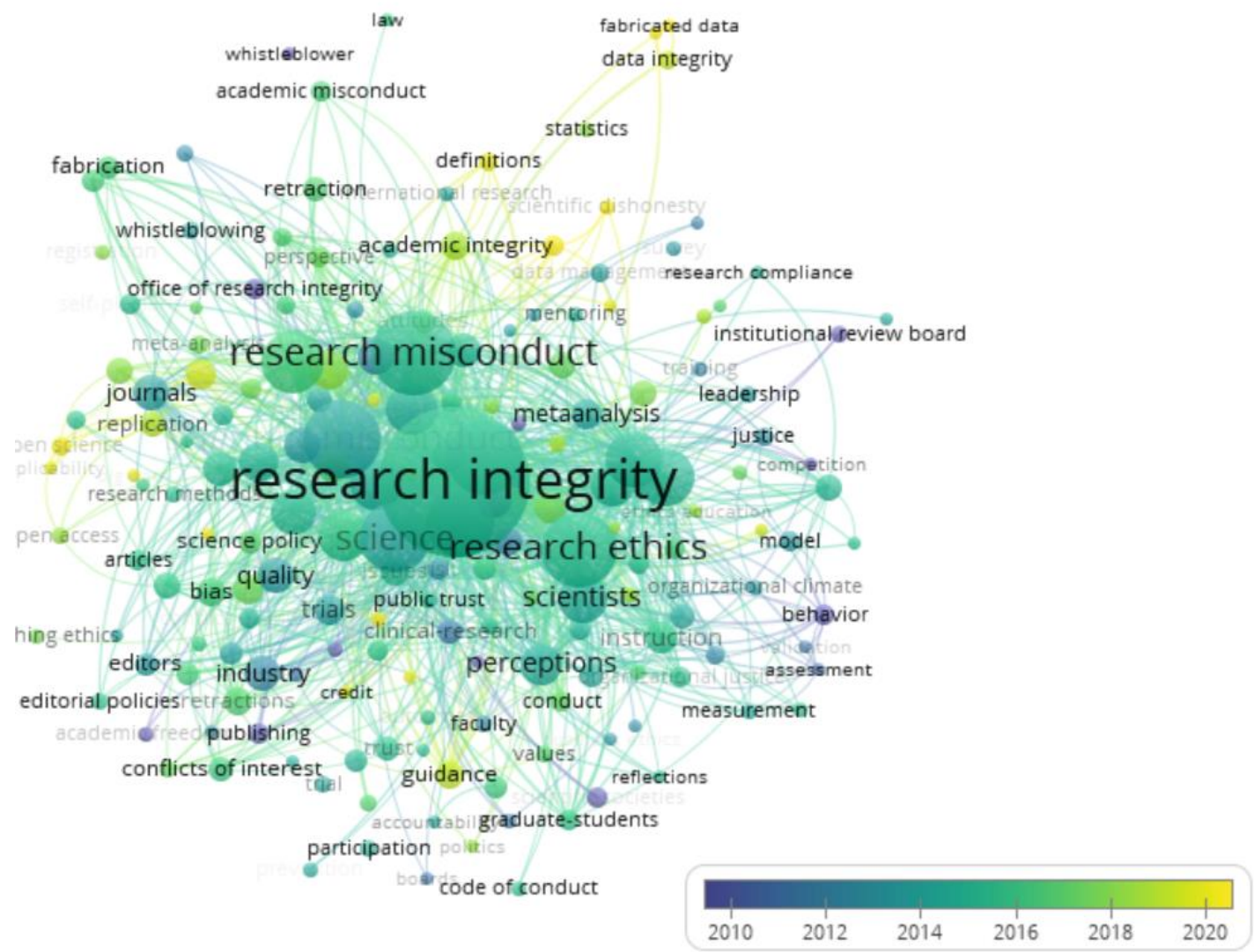

Figure 2. Results of Constructing a Map of Keywords Related to the Query "Research Integrity" (Data - DB Web of Science, Tool for Constructing a Map - VOS Viewer)

Source: Compiled by the authors

A comparative analysis of keywords showed that the phrases "research integrity" in the articles indexed by the Scopus database are mainly related to medical research, violations of research integrity in general, university activities and state regulation and economics. The last two directions provide a basis for the assertion of the 
indirect relationship of the research integrity impact on the state's economic development. In the articles indexed by the Web of Science database, the phrase "research integrity" is related exclusively to violations of research integrity and attributes of the scientist's activity (meta-analysis, publishing activity, conflict of interest, etc.). This conclusion is logical because various journals are indexed by Scopus and Web of Science databases. In the first case, these are journals of the medical and socio-humanitarian field, in the second journals and books on the research integrity and pedagogy. Thus, the further search will be carried out based on the articles indexed by the Scopus database. The SciVal tool is used to further search for topics and clusters of topics related to the "research integrity" query. Using this tool will expand the scope of searches by highlighting related topics within a keyword phrase. The results of bibliometric analysis using this tool are presented in Figures 3-6. Analysis of Figure 3 shows that "Business, Management and Accounting" takes the third place among the identified areas, where there is a demand for "research integrity". This fact gives grounds for further search in this field of knowledge because it is the "bridge" between research and commercialization of their results.

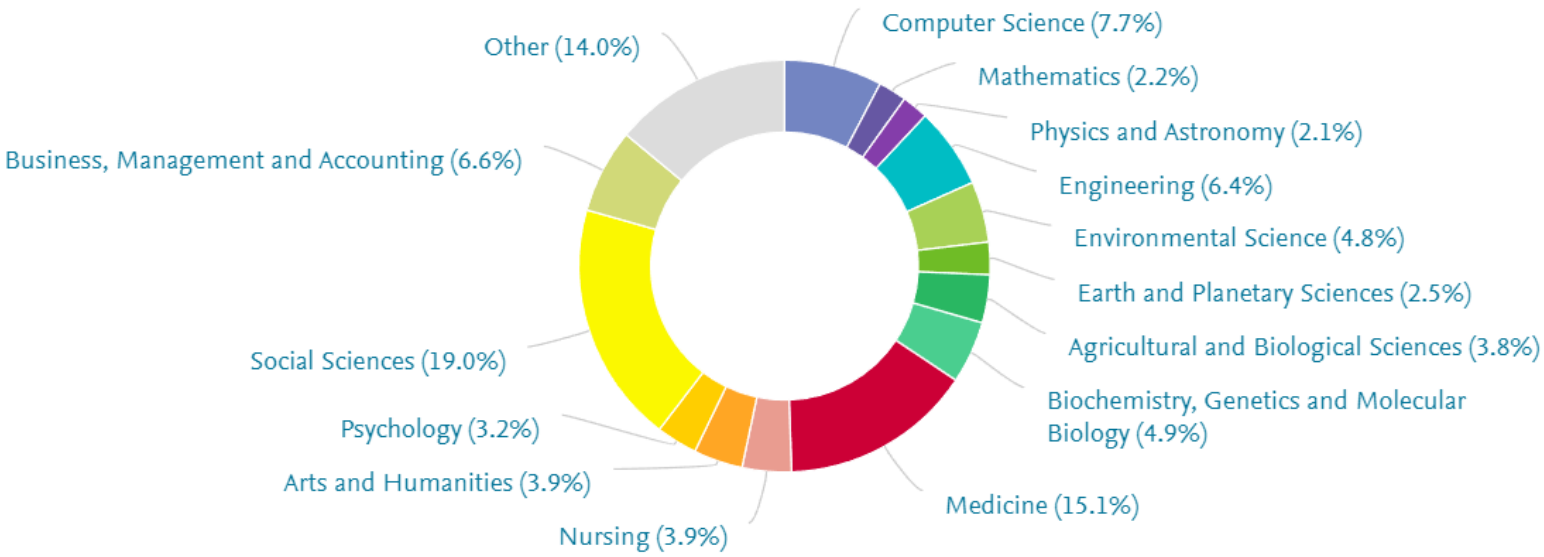

Figure 3. Fields of Knowledge, Related to Search Query "Research Integrity"

Source: Compiled by the authors, Publications by Subject Area, https://www.scival.com

The results of bibliometric analysis shown in Figures 4, 5 confirm the assumption of a direct relationship between research integrity, innovation networks, business university, economic growth, innovation, production, which is a feature of description in the analyzed works of technology transfer mechanisms. The clusters distinguished in Figure 5a according to Figure 5b have a high percentage, which indicates the relevance of the study regarding the relationship between the process of generating ideas for innovation (with respect for research integrity) and the commercialization of these ideas.

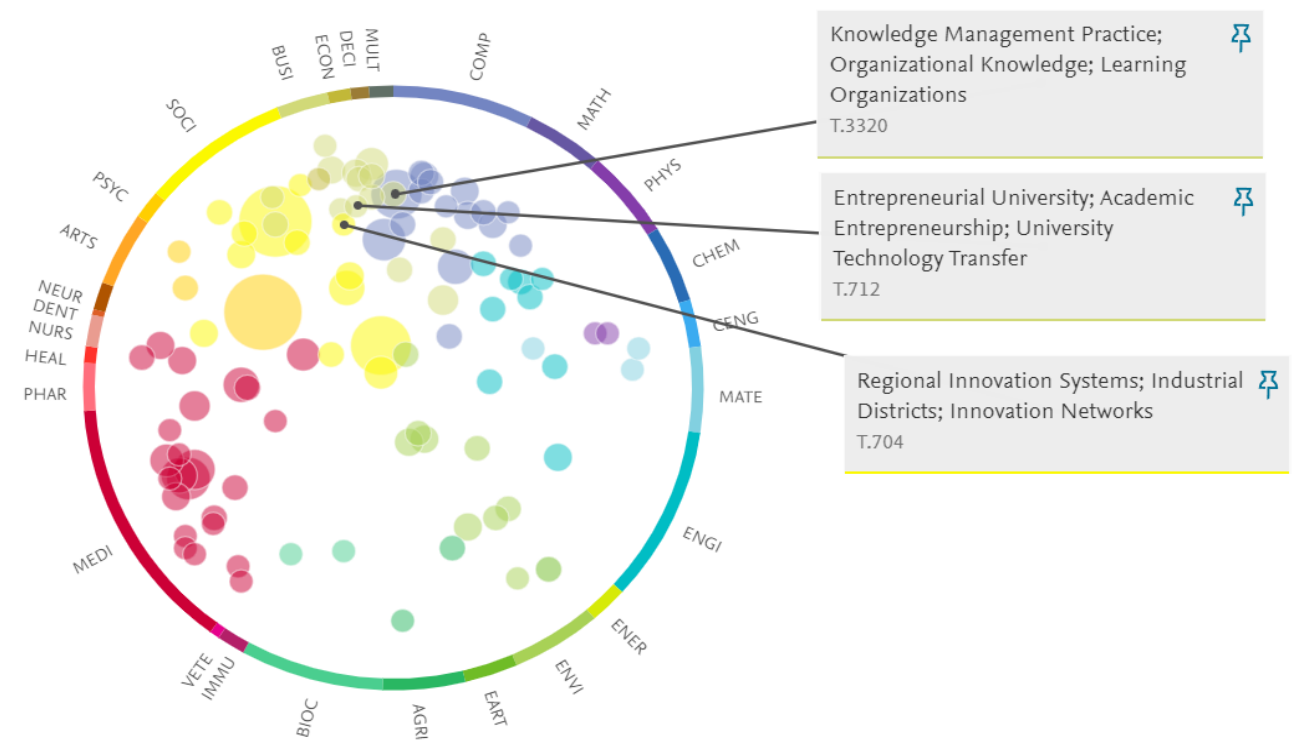

Figure 4. Topics of Related Areas of Publishing Activity on Request "Research Integrity" (Top 5\% Worldwide Topic by Prominence)

Source: Compiled by the authors, https://www.scival.com 


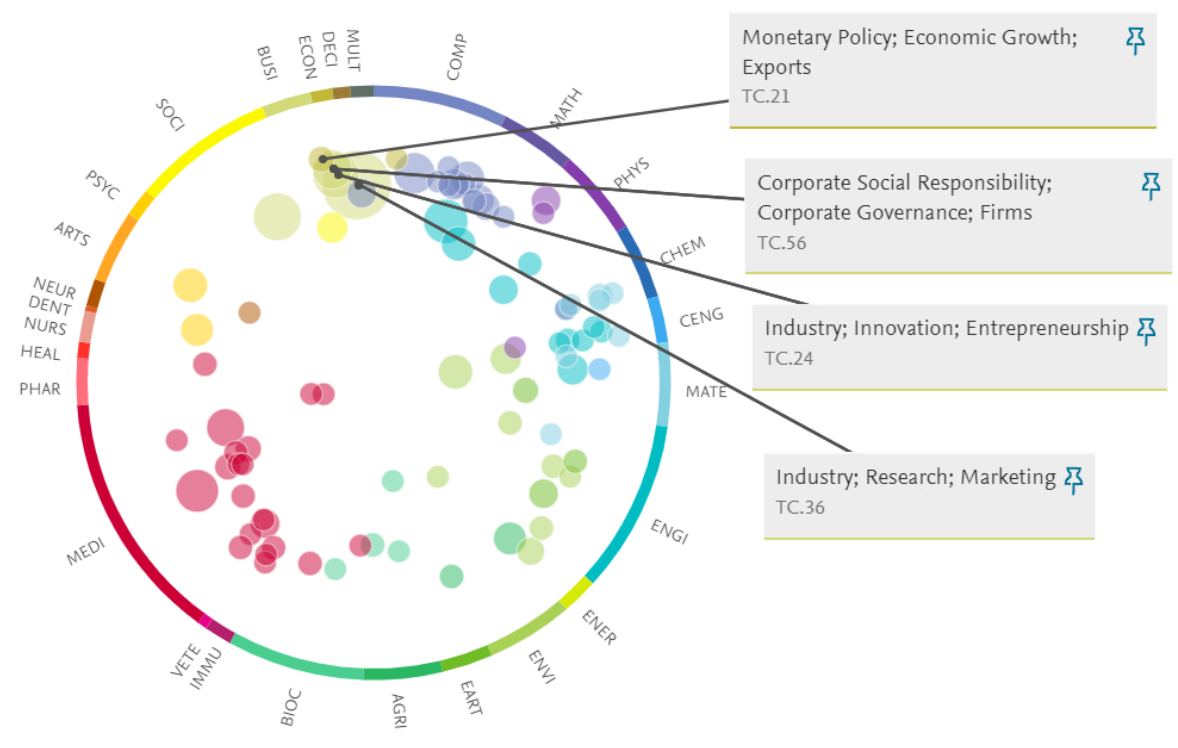

a

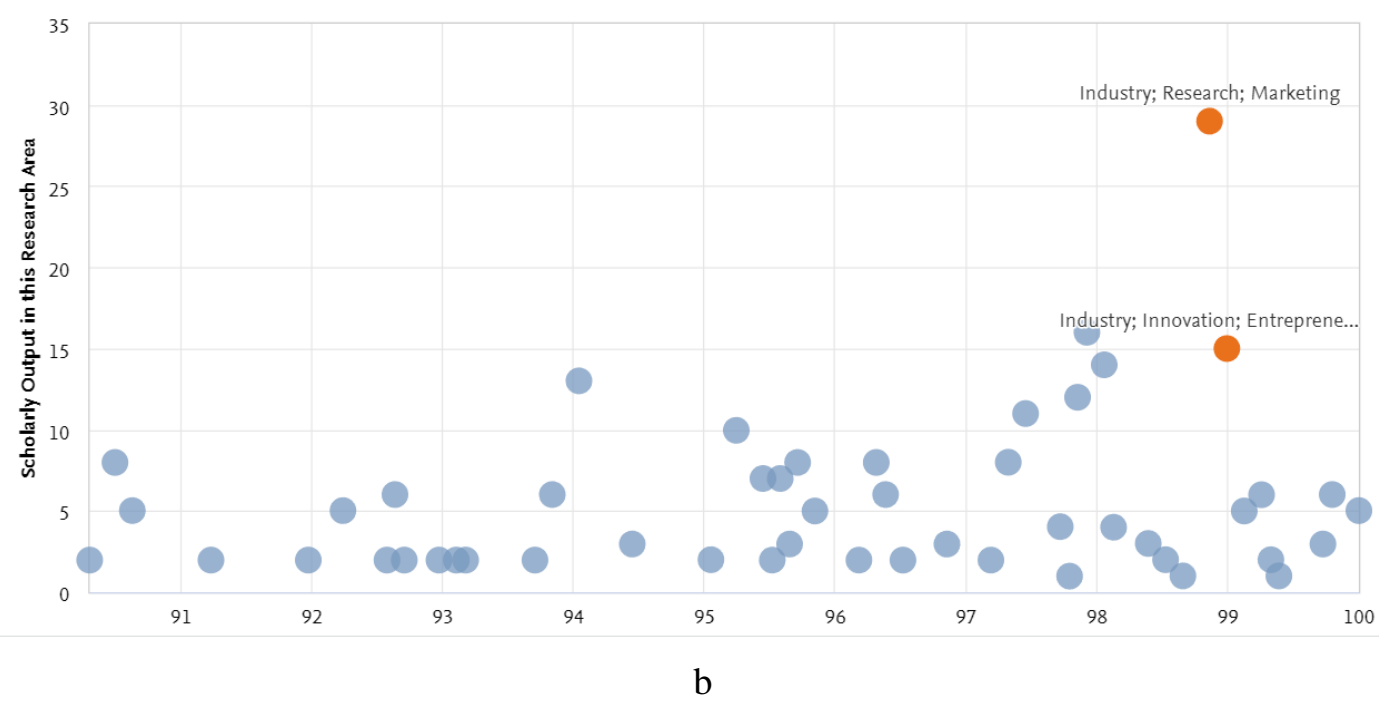

Figure 5. Clusters of Publishing Activity on Request "Research Integrity": a - Top 10\% Worldwide Topic Clusters by Prominence: b - Prominence Percentile

Source: Compiled by the authors, https://www.scival.com

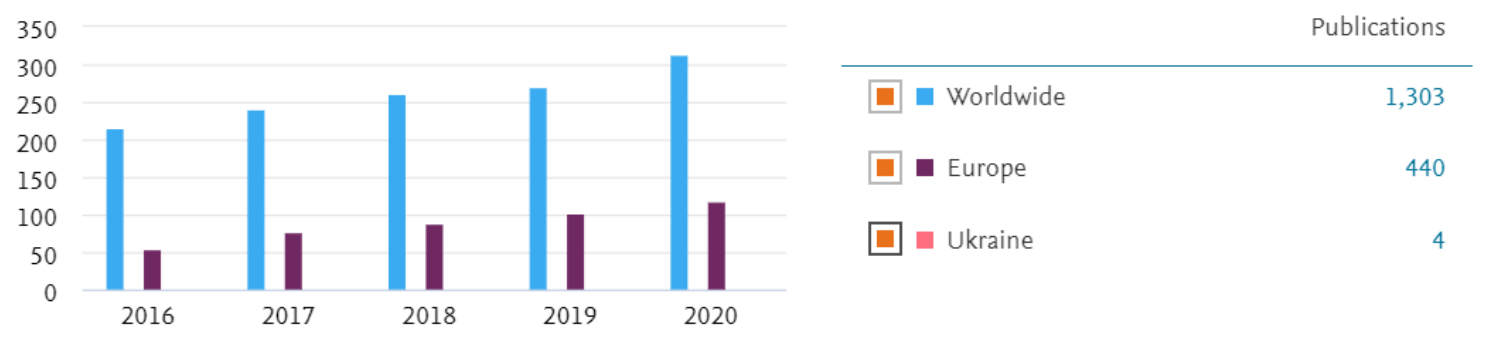

Figure 6. Number of Publications in the Period 2016-2020 on Request "Research Integrity"

Source: Compiled by the authors https://www.scival.com

Analysis of the data in Figure 6 shows that over the last five years, the number of articles on research integrity has been approximately 1,300, which is a small index compared to, for example, the Scopus database query for technology transfer (about 10,000 articles). Ukrainian scientists have published only four articles on this topic during this period. One of these articles (Zharikova et al., 2019) deals with studying the "relationship" between research and commercialization of their results through the prism of research integrity. This topic for domestic scientists is a field for further in-depth study, which further indicates the relevance of the issue, revealed in this article. 
The obtained logical links "quality of scientific activity - technology transfer - research integrity", "business education - science" require the need to transfer them into the global and local plane. The global level can be reflected in the relationship of individual goals of sustainable development (Figure 7), local - in the form of the relationship of internal quality of research with external quality monitoring from the Ministry of Education and Science of Ukraine and independent quality assurance agencies, in particular Agency for Quality Assurance in Higher Education in the Accreditation of Educational and Scientific Programs at the Educational Level "Doctor of Philosophy").

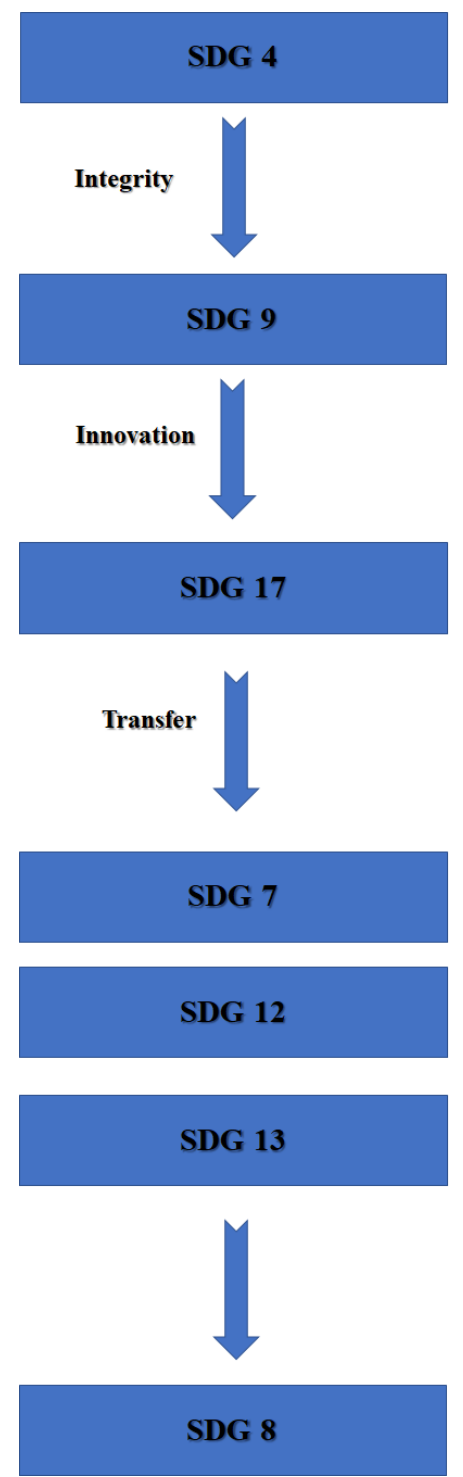

Figure 7. Global Level "Relationships of Scientific Activity Quality - Technology Transfer - Research Integrity", Source: Compiled by the authors

"Business - Education - Science"

Below there are risks related to implementing a technology transfer process at the development stage, which may be accompanied by a breach of research integrity in the format of "risk - potential breach".

1. State level:

reduction of state funding for science - the struggle for funding with the overestimation of indicators;

imperfect mechanisms for the distribution of budget funding;

imperfect regulatory framework - a point increase in indicators for the implementation of tender requirements.

2. Scientists and their relation to business: 
technologies are not brought to the level of commercialization, cannot pass the technological audit, there are no experimental samples, business plans - data manipulation to artificially increase the technological and innovative level of development readiness for implementation;

$>$ management of universities and research institutions is not ready to work in competition with other research institutions - data manipulation to artificially increase the technological and innovative level of readiness to develop and implement the apparent competitiveness of development;

$>$ the need for additional funding to bring developments to a commercial level - data manipulation to seemingly increase the importance of development.

\section{Business interest:}

most innovative projects will pay off the cost of their implementation only in the case of large-scale industrial production - data manipulation to artificially reduce the payback period of development;

risks in product development - hiding risks;

$>$ corruption that affects the investment climate - agreements with business representatives, donors to gain non-competitive advantages of development in the market.

This way can provide the regulation of the process to ensure research integrity. The normative base of Sumy State University (https://normative.sumdu.edu.ua) in terms of ensuring academic integrity determines that "In implementing all areas of scientific activity, Vice-Rector for Research Work regulates the academic integrity. Control over the observance of research integrity, implementation of measures to prevent research dishonesty in the implementation of certain areas of scientific activity is carried out in part:

activities of scientific journals at the university - by the Center for Scientific, Technical and Economic Information and by Editors-in-Chief of scientific journals;

$>$ carrying out of university scientific, scientific-practical, scientific-technical and scientific-methodical actions (conferences, meetings, symposiums, seminars, etc.) - by the Center of scientific-technical and economic information and by Chairmen of organizing committees;

$>$ protection of intellectual property rights - by the Center for Scientific, Technical and Economic Information;

$>$ performance of research works - by research part, quality monitoring group of scientific projects in its composition and supervisors of research works.

\section{Conclusions}

Research results show that there is a strong relationship between the concepts "quality of research", "technology transfer" and "research integrity", which has not received enough attention. This relationship is proven by bibliometric analysis. The main problems of the technology transfer development between the university and industry at the national level are analyzed. A separate block of problems related to research integrity is identified. The national university case on the creation of a university system to maintain the research integrity and development of infrastructure to provide the scientific activity within the limits of the specified system is given. The work results can be useful for the triangle "business - education -science" to reconcile the interests of all "vertices" of the triangle while fulfilling the mandatory condition - ensuring the quality of educational and research activities in universities as centers of intellectual potential.

Author Contributions: Conceptualization: Artem Artyukhov and Iurii Volk; methodology: Iurii Volk; software: Artem Artyukhov; validation: Artem Artyukhov, Iurii Volk, Jan Krmela, and Vladimira Krmelova; formal analysis: Jan Krmela, and Vladimira Krmelova; data curation: Iurii Volk; writing-original draft preparation: Artem Artyukhov; writing-review and editing: Artem Artyukhov, Jan Krmela, and Vladimira Krmelova; visualization: Iurii Volk; supervision: Artem Artyukhov; project administration: Artem Artyukhov.

Funding. This research was funded by the Ministry of Education and Science of Ukraine, projects "Reforming the lifelong learning system in Ukraine for the prevention of the labor emigration: a coopetition model of institutional partnership" (reg. n. 0120U102001) and "Convergence of economic and educational transformations in the digital society: modeling the impact on regional and national security" (reg. $n$. 0121U109553).

\section{References}

1. Arenas, J.J., González, D. (2018). Technology Transfer Models and Elements in the University-Industry Collaboration. Administrative sciences, 8, paper №19. [Google Scholar] [CrossRef] 
2. Cabaleiro-Cerviño, G., Vera, C. (2020) The Impact of Educational Technologies in Higher Education. GIST. Education and Learning Research Journal, 20, 155-169. [Google Scholar] [CrossRef]

3. Coeli, C.M., Luciana de Lima, L.D., \& Carvalho, M.S. (2018). Hypercompetition and research integrity. Cadernos de Saúde Pública, 34(1), 1-2. [Google Scholar] [CrossRef]

4. Daniel, A.D., Alves, L. (2020). University-industry technology transfer: the commercialization of university's patents. Knowledge Management Research \& Practice, 18(3), 276-296. [Google Scholar] [CrossRef]

5. Dźwigoł, H. (2021). Leadership in the Research: Determinants of Quality, Standards and Best Practices. Business Ethics and Leadership, 5(1), 45-56. [Google Scholar] [CrossRef]

6. Edwards, M.A. \& Roy S. (2017). Academic Research in the 21st Century: Maintaining Scientific Integrity in a Climate of Perverse Incentives and Hypercompetition. Environmental Engineering Science, 34(1), 51-61. [Google Scholar] [CrossRef]

7. Fauzan, R., Gooneratne, N. (2019). Working with the University Technology Transfer Office. Academic Entrepreneurship for Medical and Health Scientists, 1(3), Article 6. [Google Scholar] [CrossRef]

8. Govind, M., Küttim, M. (2016). International Knowledge Transfer from University to Industry: A Systematic Literature Review. Research in economics and business: Central and Eastern Europe, 8(2), 5-25. [Google Scholar]

9. Leahey, E. (2016). From Sole Investigator to Team Scientist: Trends in the Practice and Study of Research Collaboration. Annual Review of Sociology, 42, 81-100. [Google Scholar] [CrossRef]

10.Li, X., Tan, J. (2020). Exploring the Role of University-Run Enterprises in Technology Transfer from Chinese Universities. Management and Organization Review, 16(4), 907-943. [Google Scholar] [CrossRef]

11.Liuta, O. \& Artyukhov A. (2017). Academic integrity in Ukrainian higher education: values, skills, actions. Business Ethics and Leadership, 1(1), 34-39. [Google Scholar] [CrossRef]

12.Mazurkiewicz, M., Liuta, O, Kyrychenko, K. (2017). Internal Quality Assurance System for the Higher Education: Experience of Ukraine and Poland. Business Ethics and Leadership, 1(4), 74-83. [Google Scholar] [CrossRef]

13.Miller, K., McAdam, R., McAdam, M. (2018). A systematic literature review of university technology transfer from a quadruple helix perspective: toward a research agenda. $R \& D$ Management, 48, 7-24. [Google Scholar] [CrossRef]

14.Piroozi, H. (2017). From TPP to University: Transforming Technology Transfer. Science and Technology Law Review, 235, Article 11. [Google Scholar]

15.Porev, S. \& Sandyga, I. (2016). Indicators of science that are critical for creation of Ukrainian research universities. Marketing and Management of Innovations, 3, 246-262. [CrossRef]

16.Pujotomo, D.H., Hassan, S.A.H.S., Ma'aram, A., Sutopo, W.A. (2020). Systematic Literature Review of Technology Transfer Office: Research Trends, Methods, and Topics. Proceedings of the 5th NA International Conference on Industrial Engineering and Operations Management Detroit, Michigan, USA, 1063-1076. Available at: [Link]

17.Shaw, D. \& Satalkar, P. (2018). Researchers' interpretations of research integrity: A qualitative study. Accountability in Research. Policies and Quality Assurance, 25(2), 79-93. [Google Scholar] [CrossRef]

18.Schoenherr, J.R. (2015). Scientific integrity in research methods. Frontiers in Psychology, 6(1562), 1-5. [Google Scholar] [CrossRef]

19.Schrankler, J. (2018). The Role of University Technology Transfer. Medical Innovation, Academic Press, 31-41. [Google Scholar] [CrossRef]

20.Van der Heiden, P., Pohl, C., Mansor, S.B., van Genderen, J. (2015). The role of education and training in absorptive capacity of international technology transfer in the aerospace sector. Progress in Aerospace Sciences, 76, 42-54. [Google Scholar] [CrossRef]

21.Weckowska, D.M. (2015). Learning in university technology transfer offices: transactions-focused and relations-focused approaches to commercialization of academic research. Technovation, 41-42, 62-74. [Google Scholar] [CrossRef]

22.Zharikova, M. \& Sherstjuk, V. (2019). Maintaining scientific integrity through academic-industrial research and development cooperation. CEUR Workshop Proceedings, 2387, 398-408. [Google Scholar] 